\title{
ELECTRON MICROSCOPY OF CYTOPLASMIC CRYSTALLOIDS IN RAT PAROTID GLANDS
}

\author{
B. TANDleR ${ }^{1}$, J. H. Lillie ${ }^{2}$ and D. K. MacCallum ${ }^{2}$ \\ ${ }^{1}$ Department of Oral Biology and Medicine, School of Dentistry, Case Western Reserve University, \\ Cleveland, $\mathrm{OH} 44106$ \\ ${ }^{2}$ Department of Anatomy, University of Michigan Medical School, Ann Arbor, MI 18101, U.S.A.
}

\begin{abstract}
Summary-Crystalloid-containing bodies that may be lysosomes were observed by electron microscopy in acinar and striated duct cells of normal fasted rat parotid glands. The crystalloids varied in number from animal to animal and from lobule to lobule. They consisted of either parallel linear densities with a $5.5 \mathrm{~nm}$ periodicity, or of alternating major dense and minor light lines, with a $15 \mathrm{~nm}$ distance between successive major lines. It was concluded that the presence of a few such crystalloids in parotid glands of treated rats is not a cytopathic effect and they are significant only when present in large numbers.
\end{abstract}

\section{INTRODUCTION}

Cytoplasmic crystalloids, with and without limiting membranes, occur normally in a variety of glands, such as thyroid (Nunez, Gould and Holt, 1970; Elvin, 1971; Nève and Wollman, 1973) and exocrine pancreas (Forsmann and Metz, 1976), in many different organisms. Moreover, crystalloids can be induced to form in these and other organs when animals are subjected experimentally to the appropriate physiological, pharmacological or nutritional stress.

In the course of an ultrastructural study of rat parotid gland, we have found crystalloids in the glands in normal fasted animals.

\section{MATERIALS AND METHODS}

Ten male Sprague-Dawley rats (Spartan Research Animals, Inc., Haslett, Michigan) weighing 175-200 g were used. The rats were acclimatized to their laboratory cages for at least one week and fasted for 24 hours before being killed; water was freely available. The rats were anaesthetized with either chloral hydrate or sodium barbital and the parotid glands perfused via the left ventricle with room-temperature, half-strength Karnovsky (1965) fixative buffered with phosphate; after death the glands were extirpated and immersed in the same fixative for two hours. Postfixation in 1 per cent osmium tetroxide in the same buffer was carried out for two hours. Pieces of the glands were dehydrated in graded ethanols and embedded in Epon:Araldite (Mollenhauer, 1964). Thin sections were sequentially stained with uranyl acetate and lead citrate (Reynolds, 1963), and examined in a Philips 300 electron microscope.

\section{RESULTS}

Crystalloid-containing bodies were present in the glands of nearly all rats examined. Abundance varied from animal to animal; the bodies were abundant in some rats, but sparse in others. Moreover, their number varied from lobule to lobule in the same gland.
Cytoplasmic crystalloids were observed in two major structures: acinar cells and columnar cells of the striated duct. The morphology of both types of cell was unaffected by the presence of the crystals, and has been described elsewhere (Tandler, 1978).

In acinar cells, crystalloid-containing bodies were always between cisternae of the basally-located rough endoplasmic reticulum (RER). The crystalloids were elongated, rod-like structures bounded by a single smooth-surfaced membrane and tended to occur in pairs (Figs 1-3). They measured up to $5 \mu \mathrm{m}$ in length (Fig. 1) and about $0.2 \mu \mathrm{m}$ in width. Individual membraneous envelopes usually held a single crystalloid, but occasionally encompassed two closely-apposed crystalloids separated by a narrow electron-lucent space.

The periodic structure of the crystalloids became apparent at high magnification (Fig. 4). Regardless of crystal tilt with respect to the plane of section, there was only one axis of symmetry. Crystalloids with the simplest structure consisted of longitudinally-oriented linear densities with a $5.5-\mathrm{nm}$ periodicity (Fig. 4). Other crystalloids had major dense lines separated by $15-\mathrm{nm}$ intervals alternating with thinner lines of lower density. A few crystalloids appeared to consist of a composite of these two basic substructural configurations (Fig. 5). One showed a defect in its lattice in the form of a small, lucent rectangle (Fig. 6).

Most crystalloids were snugly encased by their limiting membrane with no matrix material. Some had a few small lipid-like inclusions between their outer surface and the surrounding membrane (Fig. 7). Other crystalloids were embedded in a moderatelydense matrix; in a few such crystalloids, the membrane bulged outward to accommodate accumulations of matrix material closely resembling the contents of nearby lysosomes (Fig. 8).

Crystalloids in the striated duct cells showed no preferential location and were observed in both apical and basal cytoplasm (Fig. 9). They resembled those in the acinar cells, but appeared to be more loosely enclosed by their covering membrane. Small lipid-like inclusions were present in some of these crystalloids. 


\section{DISCUSSION}

Scott and Pease (1964) described acinar cell crystalloids in parotid glands of post-prandial rats and in pilocarpine-stimulated rats during the period when zymogen granules were re-accumulating. Because Scott and Pease used methacrylate embedding and low-resolution electron microscopy, it is not possible to see the membrane status of the crystalloids in their illustrations. They said that some of these inclusions were within RER cisternae and that others niay liave had a smooth membrane or no membrane at all. Leeson (1967) states that the crystalloids are most abundant and at their largest 4-6h after stimulation. Hand (1973) found that crystalloids become noticeable about $8 \mathrm{~h}$ after re-feeding, increased in number for the next $48 \mathrm{~h}$ and had a 7-nm periodicity. Crystalloids also occur in parotid acinar cells of rats treated with actinomycin D (Adkins, 1972) but the membrane status of these inclusions is uncertain. According to Adkins and Moule (1973), crystalloids forming in parotid acinar cells as a result of injection with azathioprine are delimited by a single membrane, but whether this membrane is smooth or rough-surfaced they do not say. In rats fed with ethionine, the ethyl analogue of methionine, Leeb (1975) found crystalloids in parotid acinar cells in smooth-surfaced membranes in the region of the Golgi apparatus and lying free in the cytosol between RER cisternae. At $48 \mathrm{~h}$ after ligation of Stenson's duct of the rat, crystalloids appear in acinar serous cells (Donath, Hirsch-Hoffmann and Seifert, 1973).

Cytoplasmic crystalloids in parotid glands may have several different sources. Those that occur within RER cisternae probably represent proteinaceous secretory products that have precipitated as a result of pharmacological interference with the normal secretory pathway. This is certainly the case in acinar cells of the exocrine pancreas in rats administered the amino acid analogue, parachlorophenylalanine (Forsmann and Metz, 1976; Metz and Forsmann, 1976). This agent may produce irreversible physico-chemical alterations in the secretory proteins, leading to the widespread appearance of intracistcrnal crystalloids.

Leeb (1975) suggested that parotid crystalloids, resulting from ethioninc intoxication, are formed in the Golgi complex but produced no direct evidence that this is their place of origin. Oliver and Hand (1976) noted that, in rats fed with ethionine, autophagic vacuoles containing recognizable secretory granules were prominent by the third day of the experimental diet. By the fifth day, crystalloids began to appear within these vacuoles, and by day 7 showed typical crystal $(7 \mathrm{~nm})$ structure. The vacuoles were positive for both acid phosphatase and peroxidase, demonstrating their lysosomal nature.

Because of the appearance of their encompassing matrix and membranes, we conclude that the crystalloids we observed were also formed in lysosomes. Lysosomes with a crystal component and closely resembling those in the normal rat parotid gland have been described in a number of cell types, including those in rat terminal bronchioles (Stephens et al., 1971) and in mouse coagulating gland (Rowlatt, 1968). If the crystalloid-containing bodies in the parotid gland are indeed lysosomes, then the source of the crystal material is of some interest. Hand (1972) showed that, when rats are starved for as little as $16 \mathrm{~h}$, some parotid secretory granules show signs of degeneration. Several such granules were noted in our animals which were starved for $24 \mathrm{~h}$. As starvation is continued, Hand found that the altered granules became reactive for the lysosomal enzymes acid phosphatase and non-specific esterase, having acquired these enzymes by fusion with pre-existing lysosomes. Although the degraded secretory proteins in such fused lysosomes could conceivably assume a crystal conformation, lysosomal crystalloids were not observed within salivary parenchymal cells in Hand's large-scale study of starvation effects.

The problem of the origin of the crystalloids in normal parotid glands is complicated further by the presence of these structures in striated duct cells. It is possible that serous cell secretory protein that has been liberated into the acinat lumen, thence into the duct system, could be taken up by the striated duct cells and transferred into lysosomes. Such a process may occur in rat kidney proximal tubule cells, which have the ability to remove protein from the urine, and which have lysosomes with a crystal substructure (Maunsbach, 1966). Alternatively, as striated duct cells are capable of elaborating glycoprotein stored in small apical granules (Hand, 1978), this endogenous secretory material could serve as the source of the crystalloids if occasionally it is degraded in duct-cell lysosomes. The origin of crystalloids in salivary glands is thus still an open question.

The parotid duct crystalloids bear a superficial resemblance to the phi bodies described in mouse duct cells by Hanker and co-workers $(1977 \mathrm{a}, \mathrm{b}, \mathrm{c})$. The phi bodies, so-called because of their resemblance in thin sections to the Greek letter $\phi$, contain an axial rod composed of parallel $\sim 13-\mathrm{nm}$ tubules that in longitudinal section have a crystalline appearance. The matrix of the phi bodies is homogeneous and lacks lipid or other inclusions. They are catalasepositive, marking them as a species of peroxisome. They are not nearly as prominent in rat salivary glands as in those of the mousc. Because of their shape and their partially tubular composition, it is clear that the phi bodies are unrelated to the crystalloids we observed.

The occurrence of occasional crystalloids in salivary glands of rats stressed in various ways should not be regarded as a cytopathic effect. Only if crystalloids appear in large numbers is their occurrence significant.

Acknowledgements-This work was supported in part by N.I.H. Grants 5 S01 FR05335 and DE 02731.

\section{REFERENCES}

Adkins K. F. 1972. Structural changes in parotid acinar cells following administration of actinomycin-D. Alabama J. med. Sci. 9, 321-326.

Adkins K. F. and Moule A. J. 1973. Drug-induced xerostomia: cellular changes produced in parotid acinar cells by azathioprine. N. Zeal. dent. J. 69, 112-120.

Donath K., Hirsch-Hoffmann H.-U, and Seifert G, 1973. Zur Pathogenese der Parotisatrophie nach experimenteller Gangunterbindung. Ultrastrukturelle Befunde am 
Drüsenparenchym der Rattenparotis. Virchows Archs Abt. A. path. Anat. 359, 31-48.

Elvin L.-G. 1971. Cytoplasmic bodies with a crystalline substructure in the follicular cells of the mouse thyroid gland. J. Ultrastruct. Res. 34, 345-357.

Forsmann W. G. and Metz J. 1976. Exocrine pancreas under experimental conditions. I. Formation of paracrystalline inclusions in vivo. Cell Tiss. Res. 171, $467-482$.

Hand A. R. 1972. The effects of acute starvation on parotid acinar cells. Uitrastructural and cytochemical observations on ad libitum fed and starved rats. $1 \mathrm{~m}$. J. Anat. $135,71-92$.

Hand A. R. 1973. Secretory granules, membranes, and lysosomes. In: Symposium on the Mechanism of Exocrine Secretion (Edited by Han S. S., Sreebny L. and Suddick R.) pp. 129-151. University of Michigan Press, Ann Arbor, Mich.

Hand A. R. 1978. Radioautographic study of glycoprotein synthesis by striated duct cells of rat salivary glands. J. dent. Res. 57A, 247.

Hanker J. S., Preece J. W., Burkes E. J., Jr. and Romanovicz D. K. 1977a. Catalase in salivary gland striated and excretory duct cells. I. The distribution of cytoplasmic and particulate catalase and the presence of catalasepositive rods. Histochem. J. 9, 711-728.

Hanker J. S. and Romanovicz D. K. 1977b. Phi bodies: peroxidatic particles that produce crystalloid cellular inclusions. Science 197, 895-898.

Hanker J. S., Silverman M. S. and Romanovicz D. K. 1977 c. Catalase in salivary gland striated and excretory duct cells. II. $\phi$ body; an ellipsoidal peroxisomal organelle with crystalloid axial projections. Histochem. J. 9, 729-744.

Karnovsky M. J. 1965. A formaldehyde-glutaraldehyde fixative of high osmolality for use in electron microscopy. J. Cell Biol. 27, 137A-138A.

Leeb I. J. 1975. Ethionine induced degeneration and regeneration in the rat parotid gland: An electron microscope study. Am. J. Anat. 142, 29-46.
Leeson C. R. 1967. Structure of salivary glands. In: Handbook of Physiology (Edited by Codc C. F.) Vol. 2, Sect. 6, pp. 463-495. American Physiological Society, Washington, D.C.

Maunsbach A. B. 1966. Electron microscopic observations of cytoplasmic bodies with crystalline patterns in rat kidney proximal tubule cells. $J$. Ultrastruct. Res. 14, 167-189.

Metz J. and Forsmann W. G. 1976. Exocrine pancreas under experimental conditions. II. In vitro formation of paracrystalline structures and its functional consequences. Cell Tiss. Res. 173, 221235.

Mollenhauer H. H. 1964. Plastic embedding mixtures for use in electron microscopy. Stain Technol. 39, 111-114.

Nève P. and Wollman S. H. 1973. Crystals in dense bodies in the typical thyroid epithelial cell of the I mouse. $J$. natl Cancer Inst. 51, 659-665.

Nunez E. A., Gould R. P. and Holt S. J. 1970. Seasonal changes in secretory granules and crystalloid inclusions of bat thyroid parafollicular cells. J. Cell Sci. 6, 821-841.

Oliver C. and Hand A. R. 1976. Effects of ethionine on rat parotid acinar cells. J. Cell Biol. 70, 60a.

Reynolds E. S. 1963. The use of lead citrate at high $\mathrm{pH}$ as an electron-opaque stain in electron microscopy. $J$. Cell Biol. 17, 208-212.

Rowlatt C. 1968. Unusual inclusions found in lysosomes of mouse coagulating gland epithelium. J. Ultrastruct. Res. 22, 393-401.

Scott B. L. and Pease D. C. 1964. Electron microscopy of induced changes in the salivary gland of the rat. In: Salivary Glands and Their Secretions (Edited by Sreebny L. M. and Meyer J.) pp. 13-44. MacMillan, New York.

Stephens R. J., Freeman G., Crane S. C. and Furiosi N. J. 1971. Ultrastructural changes in the terminal bronchiole of the rat during continuous low-level exposure to nitrogen dioxide. Exp. mol. Pathol. 14, 1-9.

Tandler B. 1978. Salivary glands and the secretory process. In: Textbook of Oral Biology (Edited by Shaw J. H., Sweeney E. A., Cappuccino C. C. and Meller S. M.) pp. 547-592. Saunders, Philadelphia. 


\section{Plate 1}

Fig. 1. Survey micrograph of parotid acinar cells showing a cell containing two crystalloids (arrows), one rather elongated, amid the RER. $\times 13,000$

Fig. 2. A pair of membrane-delimited crystalloids at the base of a serous cell. $\times 20,500$

\section{Plate 2.}

Fig. 3. A pair of acinar crystalloids with periodic substructure. $\times 85,000$

Fig. 4. A portion of the preceding micrograph at higher magnification, showing bounding unit membrane and the crystalloid substructure. $\times 204,000$

Fig. 5. An acinar crystalloid displaying a variety of interdensity spacings. Several small lipid droplets lie between the crystalloid and its membrane. $\times 65,000$

Fig. 6. An acinar crystalloid separated into two moieties by a light stratum. A small, light, rectangular defect is present in the upper portion. $\times 36,700$

\section{Plate 3.}

Fig. 7. An acinar crystalloid in a lysosome-like body. $\times 38,000$

Fig. 8. Several acinar crystalloids in lysosome-like bodies. Compare the non-crystalloid contents of these bodies with those of the autophagic vacuole at the lower right $\times 31,500$

Fig. 9. A crystalloid-containing body in the apical cytoplasm of a striated duct cell. Note the small lipid droplet at the lower end of this body. LU, lumen. $\times 14,600$ 


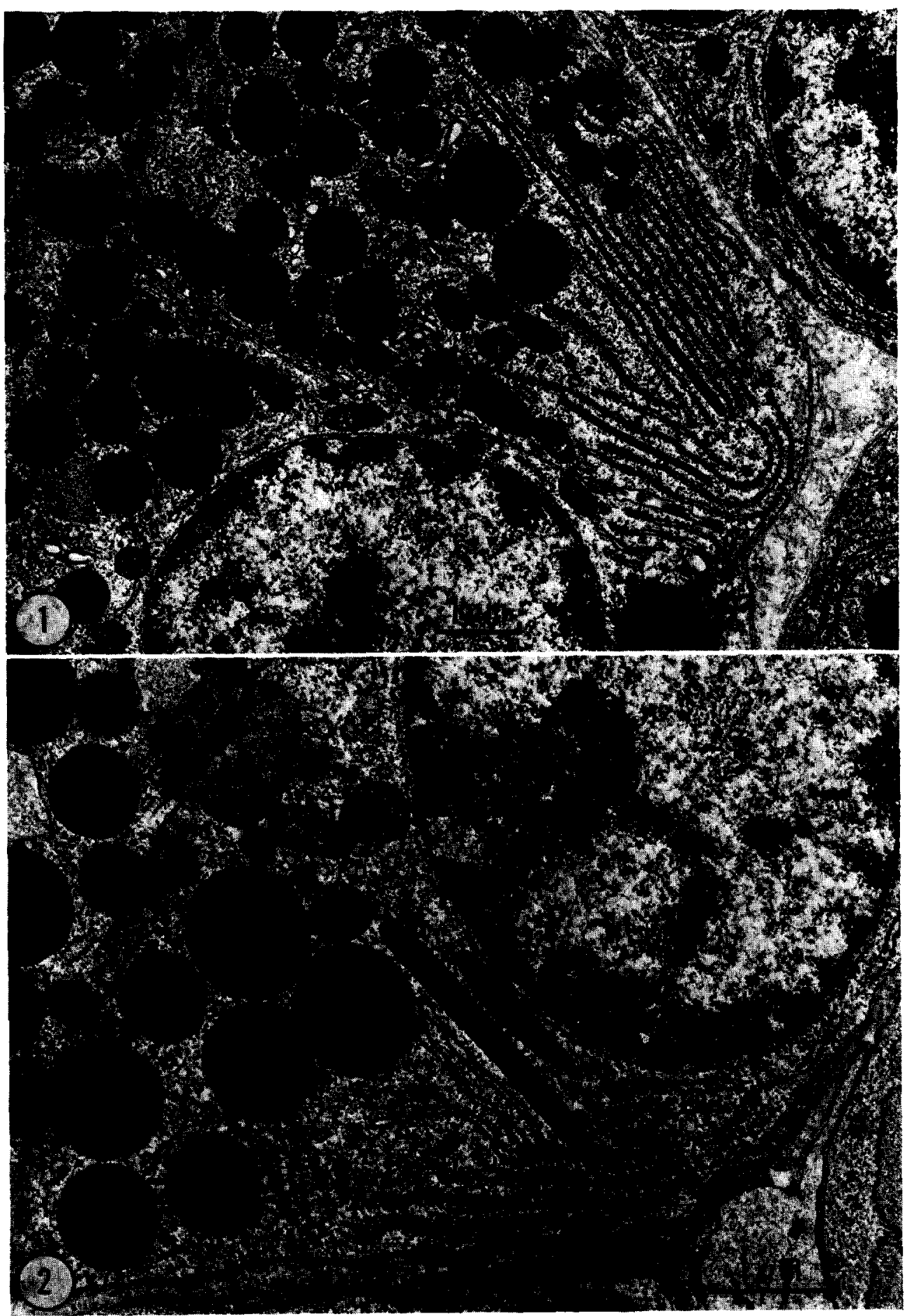

Plate 1. 

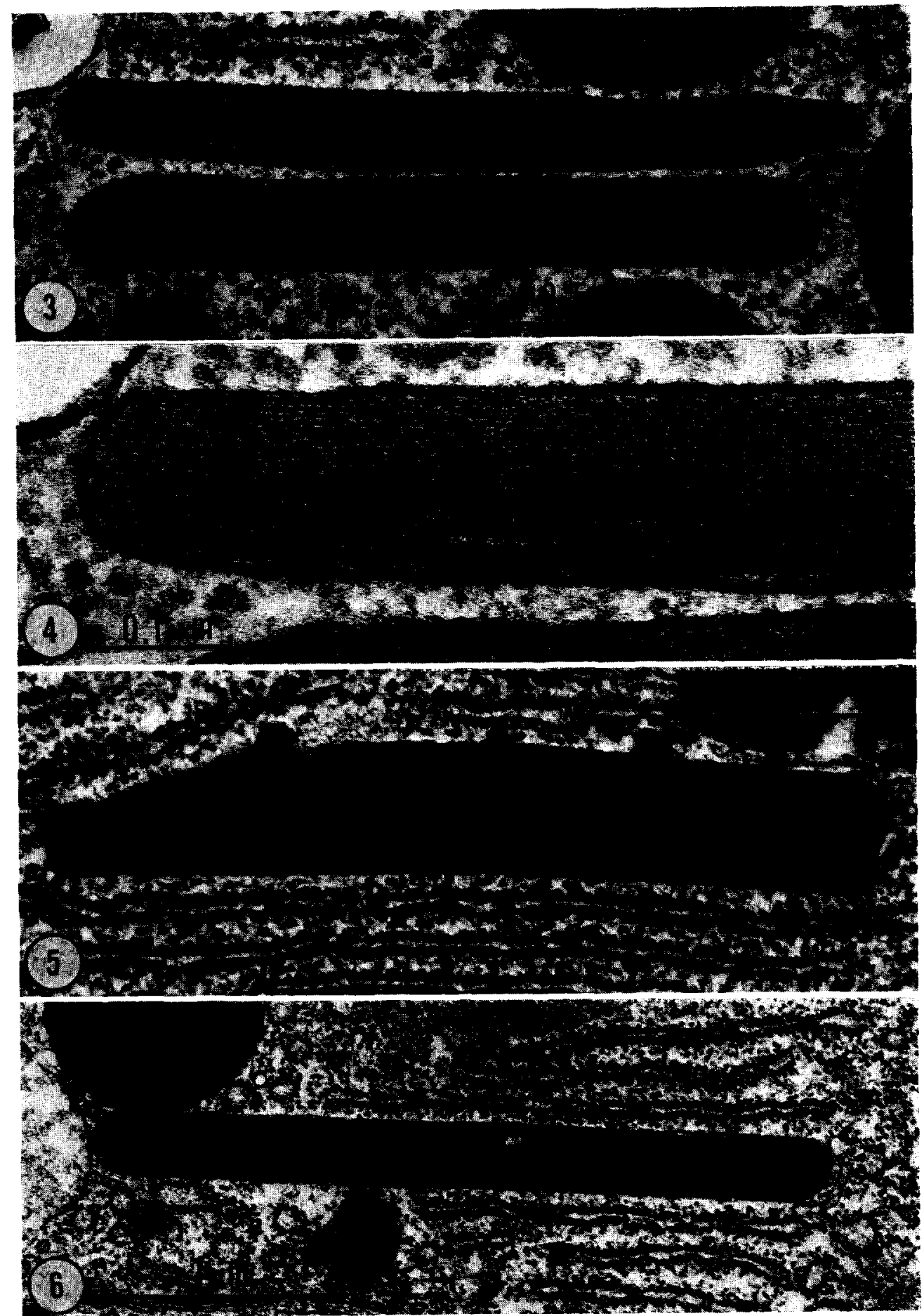

Plate 2. 


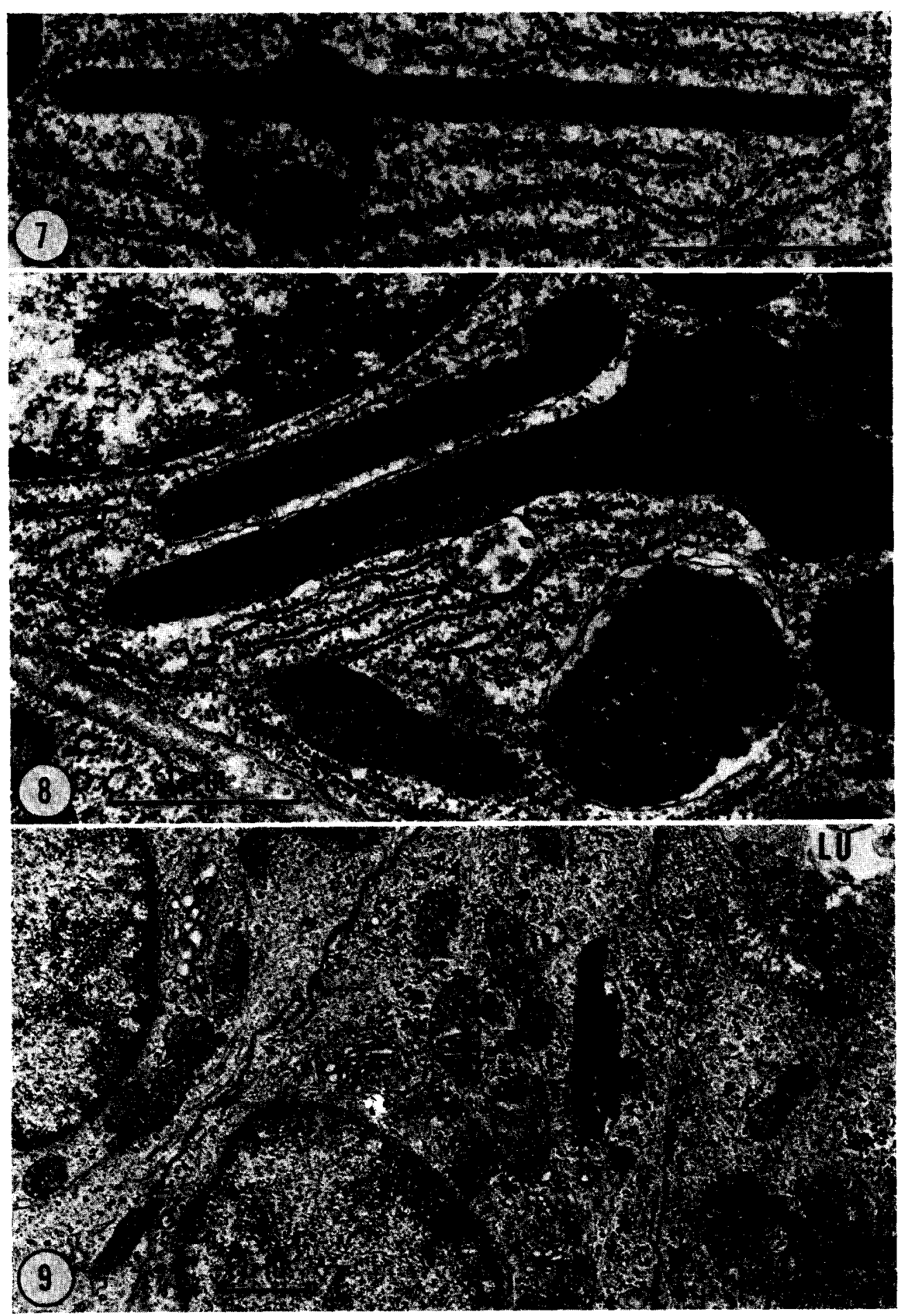

Plate 3. 